\title{
The Challenges of Using Service Learning in Construction Management Curricula
}

\author{
R. Casey Cline \\ Assistant Professor, Department of Construction Management \\ Boise State University \\ Boise, Idaho 83725 \\ ccline@boisestate.edu \\ Michael Kroth \\ Professor, Adult and Organizational Learning \\ University of Idaho \\ Boise, Idaho 83702 \\ mkroth@uidaho.edu
}

\begin{abstract}
The use of experiential learning as a pedagogical mechanism to facilitate the learning of skills taught in the classroom has become common in college curricula. Service learning and community engagement models are frequently used to combine academic skills with "real-world" experience to foster understanding, and to largely broaden the perspective of the learner. Service-learning and community engagement are both commonly used in construction management (CM) curricula to allow the CM learner to develop a greater understanding of construction materials, processes, and management techniques presented in CM coursework. CM educators, in an effort to formalize the experiential learning process into course curricula, inaccurately describe the experiential learning project as service-learning rather than community engagement because there is confusion about the parameters differentiating these two experiential models. In fact, many CM courses that include experiential learning are in fact practicing community engagement and not service-learning. It is the parameters that set these two forms of experiential learning apart that make the practice of using service-learning in CM curricula a challenge.
\end{abstract}

Index Term - Experiential learning, community engagement, service-learning, construction education

\section{INTRODUCTION}

Many construction educators and industry insiders believe a "real world" education is imperative in order to ensure students are well equipped to manage the responsibilities of the positions they will eventually hold. There are many ways to provide real world experiences for learners, most notably through apprenticeships, internships, and more recently through different forms of experiential learning including service-learning and community engagement. However, the authors have found this to be more easily done in theory than in practice. Using the experiential learning process to teach CM learners is fraught with difficulties, and prone to chaotic endeavors that serve as examples of how not to properly manage construction projects. This paper will 
describe some of the first author's experiences and provide recommendations for effectively using service learning in construction management curricula.

The first author is a previous participant in the commercial construction industry and construction management educator, and strives to provide CM learners with as much "real world" knowledge and experience as possible in an academic setting. To accomplish this goal, the CM program at the author's institution has used service-learning as part of the curricula in both its Safety and Supervision and Materials and Methods courses. The Safety and Supervision course is an upper division course that provides a traditional lecture format on topics including project management, supervision, and construction safety. The course also includes a laboratory section requiring upper division CM learners to design, estimate, construct, and manage a service-learning construction project while at the same time supervising underclassman in proper construction techniques and safety practices. The Construction Materials and Methods course is designed for students new to the CM program to develop a basic understanding of the construction process and begin to gain some insight into the process of managing a construction project. The laboratory section of this course requires students to be the labor for service-learning projects managed and supervised by the upper class students in the Safety and Supervision course.

\section{COMMUNITY ENGAGEMENT AND SERVICE-LEARNING}

Community engagement is a work process, in which groups of people affiliated by geographic proximity, special interest, or similar situations work collaboratively to address issues affecting their own well-being. Through this process environmental and behavioral changes are made to improve the health of the community and its members. Partnerships and coalitions are often formed to mobilize resources, change relationships among partners, and serve as a catalyst for changing policies, programs, and practices (Fawcett et al., 1995). Similarly, service-learning is a form of experiential education that uses a service project to use academic skills learned in the classroom to solve real problems involved on a project and learn from the project in a reflective manner (Senior, 1999). Working on relevant academically-based community service projects increases the learner's understanding of course content, gives a broader appreciation of the discipline, and enhances civic responsibility. Service-learning also allows the opportunity to practice communication, cross-cultural exposure, critical-thinking, group-work, and citizenship/community service skills ("BSU Service Learning", 2005). In addition to fostering the learning process in typical learning objectives, service-learning is also used as a character building tool, a learning component of particular importance because very few pedagogical tools are commonly used to cultivate a learner's character formation (Senior, 1999). It is important to note that service-learning differs from other types of experiential learning such as community engagement, community service, and internships where the emphasis is placed upon the service provided to the beneficiary or to the one providing the service. In service-learning both the recipient and the provider benefit from the experience (Furco, 1996). It is the differentiating parameters of community engagement and service-learning that make using service-learning in construction curricula a challenging task. 


\section{Criteria for Successful Projects}

\section{Project Selection Service Learning Construction Projects}

Burr \& Martin (2003) state construction management departments should actively seek servicelearning projects by establishing strong relationships with business, industry, and civic groups, as well as pursuing opportunities presented by learners through learner clubs and organizations. The first author has found that finding projects to perform is not a difficult task. Most non-profit agencies are more than willing to accept free construction assistance such as repairing existing facilities and/or designing and constructing new facilities. The challenge is to find projects that meet the parameters of a service-learning project. The CM service-learning project must:

1. Allow the learner to practice construction management academic skills learned in the classroom using real-life experiential learning.

2. $\quad$ Provide an opportunity for the learner to interact with project recipients.

3. Be feasible, considering the amount of time available in the specific CM course.

4. Be complex enough to allow the learner to be challenged, but not overwhelmed.

5. Contain an element that will allow for learning through reflection.

6. Include components that can be evaluated to determine the relative success of the project and the effect of the experiential learning process.

In addition to ensuring that service-learning projects meet the criteria detailed above, the instructor must be cautious when soliciting projects from non-profit agencies. Many times the mere mention of free service to an agency can put in motion a frenzy of activity that can cause the evaluation and possible rejection of a project to have significant negative consequences either for the affected agency or to the reputation of the CM program.

\section{Comprehensiveness}

When considering a potential service-learning construction project, the CM educator must determine if the project is comprehensive enough to allow the learner to practice construction management skills that are taught in the classroom. Selecting small, less comprehensive construction projects may seem desirable, but many times these projects lack complexity and do not allow the learner to put to use academic skills learned in construction management curricula. Alternatively, the complexity of larger and more comprehensive construction projects can be overwhelming in a one semester course, over taxing the time and resources of both the educator and learners. Cooperative efforts are often undertaken with non-profit entities that provide construction services to communities, such as Habitat for Humanity, to mediate the complexity of larger projects. While these cooperative projects provide learners with lessons in community engagement and civic responsibility, they usually do not allow the practice of learned construction management skills. Rarely are learners allowed to practice the estimating, scheduling, cost control, and contract management skills, or other skills commonly taught in construction management curricula. Again, it is the practice of academic 
skills learned in the classroom in combination with experiential learning that composes the service-learning model. If the practice of academic skills is not present, it is not a servicelearning project, and the work accomplished by the CM learner is more analogous to community engagement.

\section{Project Complexity}

When considering a potential service-learning construction project it is important to have a thorough understanding of the specific work activities the learner will be required to complete. It is our experience that some learners may have knowledge of a variety of different construction processes, but few bring to the construction site the wealth of knowledge and experience needed to effectively manage, construct, and most importantly solve problems that will inevitably arise on service-learning construction projects. The result of this lack of knowledge and experience gives rise to a dilemma for the CM instructor. Should he or she micromanage or allow the learner to gain experience through failure and rework? In micromanaging the project the CM instructor inevitably will assume much of the management function, relegating the function of the learner to that of an observer of the management process. On the other hand, letting the learner fail, rework, and succeed is an invaluable learning lesson, but difficult to allow when material costs, time constraints, and project recipient expectations are considered.

\section{Timeline}

We have found that an accurate assessment of the scope and timeline of the project, and also the preparedness of the person or organization the project is being conducted for is critical. More specifically, it must be determined if the project can be started and completed within the timeline set forth by the project owner, and within the time parameters of the specific CM course. We have found that a typical sixteen week semester course with two, three-hour laboratory sections per week, makes effective production difficult to achieve no matter the amount of prior planning undertaken by the learners and instructor. Much of this lack of productivity is caused by issues that plague all construction projects, including material procurement and expediting, tool and equipment availability, and the transportation of personnel, or in this case learners, to the project. Transportation of learners to the servicelearning project can be especially difficult if lab periods are slotted between other classes attended by the CM learners. Amassing the learners, transporting them, rolling-out tools, and then doing the reverse at the end of the lab period can consume the majority of the time allotted for a project.

The preparedness of the project recipient to undertake a service-learning project also must be determined. Like all construction projects, service learning projects can be greatly affected by the action or lack of action taken by the project recipient. When a servicelearning project is supposed to take place within the confines of a sixteen week CM course, any delay can mean the difference between completing the project within a single course or continuing work in an additional semester or quarter. More troublesome, while a delay in starting a project is typical in the construction industry; a few weeks delay in starting a service-learning project can result in the need to completely restructure the CM course. 


\section{Project Size}

A project must be complex enough to challenge learners, not so complex that it overwhelms both the learner and instructor, and small enough to complete within a set timeline, but it must also be large enough to assign specific and significant responsibilities to each of the learners enrolled in the course. In most cases this is not feasible, so instead multiple service-learning construction projects have been undertaken by a single class. Undertaking multiple projects has a wide range of consequences. Most importantly the instructor is forced to oversee the management of each one and there is limited contact with learners due to logistical constraints. The result is an inability to evaluate the learner, safety and liability concerns, and a general loss of control.

\section{Project Recipient Participation}

In our experience there is little connection between the learner and service project recipient. Many times the beneficiary has little knowledge nor desire to participate in the construction process. A project that involves the repair and painting of homes of migrant workers may be a valid project that provides a much needed service to a community but the CM learner loses the opportunity to practice cross-cultural and communication skills if there is no interaction with the members of the migrant community,. When the continuous learner-recipient interaction component is missing, the citizenship/community based project is more an act of community engagement than a service learning project.

\section{Reflection}

One of the basic requirements of service-learning is the use of personal reflection. Personal reflection is a process occurring when learners actively reflect on what is learned throughout the service-learning experience (Furco, 1996). Reflection can be accomplished in an academic setting through open discussion or in written forms such as journaling. Reflective journaling is a pedagogical strategy used to enhance learning, interest, and self-awareness in learners. Journaling facilitates the learning process by linking abstract concepts taught in the classroom to relevant personal experiences through introspection and self-expression (Hampton \& Morrow, 2003). Though journaling is an effective way for the learner to keep a record of his or her feelings and thoughts concerning a project, it is difficult to evaluate. To set a specific number of entries needed per week or a specific number of pages to be written in a reflection journal sets demands that may be contrary to the actual thoughts and feelings of the CM learner. By setting requirements for the reflection journal, the instructor is forcing the learner to produce script that may be genuine, or may be manufactured to fulfill the requirements of the class. Evaluating the service-learning journal is also difficult because the accuracy and authenticity of the learner's effort is subjective. Some learners will give an honest assessment of the service-learning experience, while others will give a few lines of random thoughts. Reasons for the wide variation in content may be that some learners are less comfortable providing the instructor with a truthful critique of the learning, or may be uncomfortable with expressing their personal feelings. 


\section{Evaluation}

At the onset of the service-learning construction project it is important to identify specific objectives relative to the project's success, as well as educational objectives and expectations for skill and knowledge acquisition by the CM learner (Burr \& Martin). The development of objectives and expectations for evaluating the learner is difficult because of the different types and levels of service-learning experience he or she has obtained prior to enrolling in the course. While some learners may have past construction experience, others may have no experience in actual hands-on construction processes. Those with hands-on construction experience may not have previous management experience, nor had the opportunity to develop the interpersonal skills and the personal confidence to allow for the successful management of the construction process. In either case, grading becomes a subjective practice. The instructor must have a thorough knowledge of the abilities the CM learners bring to the class and be able to evaluate the learner's relative achievements during the experiential learning process.

\section{RECOMMENDATIONS}

Experiential learning in construction management curricula, and more specifically servicelearning can be an invaluable procedure for reinforcing construction management skills presented in the CM course. Using service-learning takes much effort from the CM educator, however, and should not be undertaken without prior preparation. We recommend preparing as early as possible Paramount for the success of a service-learning project is the determination of project-specific criteria to evaluate the feasibility of potential projects. If these parameters are not met the project must not be pursued as part of a CM course.

Our recommendations for addressing the challenges described in this paper are:

1. Comprehensiveness: Determine if the project will allow learners to practice skills presented in the CM course. If the project does not allow for the practice of learned construction management skills, try to increase the scope of learner participation.

2. Complexity: Consider whether the service-learning project complexity is congruent with the abilities of the specific CM learner(s). Included in this assessment must be both the management and labor project requirements, as well the learner's ability to perform labor tasks involved in the project.

3. Timeline: The feasibility of the project timeline is key to success. Ensure that the project recipient understands the inflexibility of the course time parameters. Accurately assess the duration of the project given the abilities of the CM learner. Determine if the servicelearning project can be accomplished within the time parameter of the specific CM course or whether alternative or additional meeting times will be required.

4. Size: The size of the service-learning project should be large enough to allow each CM learner to put forth meaningful effort that reinforces skills taught in the classroom. If the project is not large enough to provide a significant experiential educational experience for the learner, consider undertaking additional projects. If this action is taken projects should be chosen in the same geographic proximity. 
5. Project Recipient / Collaboration: Ensure that the parameters of the service-learning model are fully understood by the project recipient. Define what interaction the CM learner will have with the project recipient and how this interaction will take place. Inform the project recipient that though the CM educator has expertise in the construction process, it is the collaboration of the CM learners and the project recipient that allows the service-learning process to be a success.

6. Reflection: Encourage learners to set educational objectives and goals at the beginning of the service-learning project in their personal reflective journals. Routinely review their journals and encourage students to actively participate in the reflection process. Assure learners that journal entries will be kept in confidence. Ensure that they are.

7. Evaluation: The use of educational objectives set forth by the learner in a personal reflective journal is one way to evaluate learners. Is a project that is not completed on time, budget, or within project recipient guidelines a success? Learning is the primary goal in the course, not project completion. The effort of a learner is more important than the finished product because learners bring to the course a wide range of prior knowledge and experience.

\section{CONCLUSIONS}

Experiential learning is an invaluable method of reinforcing skills taught in the classroom because it allows the learner to practice those skills in a "real world" setting. Service-learning allows the learner to learn beyond the walls of a classroom by establishing a learning environment best suited for learners to gain knowledge. Although a powerful learning process, the practice of using service-learning projects in CM curricula can be challenging due to logistical concerns, course time constraints, and by the very qualities that set service-leaning apart from other forms of experiential learning. Therefore it is imperative for the instructor of CM courses to thoroughly evaluate potential projects to make certain that they meet criteria set forth for service-learning projects, and to ensure that the project has a high potential for success given the parameters of the specific course. 


\section{REFERENCES}

BSU Service Learning. (2005). Retrieved April 7, 2005, from http://servicelearning.boisestate.edu/index.cfm.

Burr, K. L., \& Martin, J. (2003). Assessment tools for construction - education service-learning projects Paper presented at the Associated Schools of Construction 39th Annual Conference, Clemson, South Carolina.

Fawcett, S. B., Paine-Andrews, A., Francisco, V. T., Schultz, J. A., Richter, K. P., Lewis, R. K., et al. (1995). Using empowerment theory in collaborative partnership for community health and development. American Journal of Community Psychology, 23, 677-697.

Furco, A. (1996). Service-learning: a balanced approach to experiential education. In Expanding Boundaries: Serving and Learning (Vol. 1). New York, NY: The Corporation for National and Community Service.

Hampton, S. E., \& Morrow, C. (2003). Reflective journaling and assessment. Journal of Professional Issues in Engineering Education and Practice, 129(ASCE), 186.

Senior, B. A. (1999). Service-Learning: A Win-Win Resource for Construction Education. Journal of Construction Education, Vol. 4(No. 1), 17-25. 